\title{
Design of Vital Sign Monitor with ECG, BPM, and Respiration Rate Parameters
}

\author{
Gede Aditya Mahendra Oka, Andjar Pudji, Muhammad Ridha Mak'ruf, Endro Yulianto \\ Department of Medical Electronics Engineering Technology of Politeknik Kesehatan Kementerian Kesehatan Surabaya \\ Jl. Pucang Jajar Timur No. 10, Surabaya, 60245, Indonesia \\ adityamhndraoka@gmail.com,andjar.pudji@gmail.com,m.reedha@gmail.com,
}

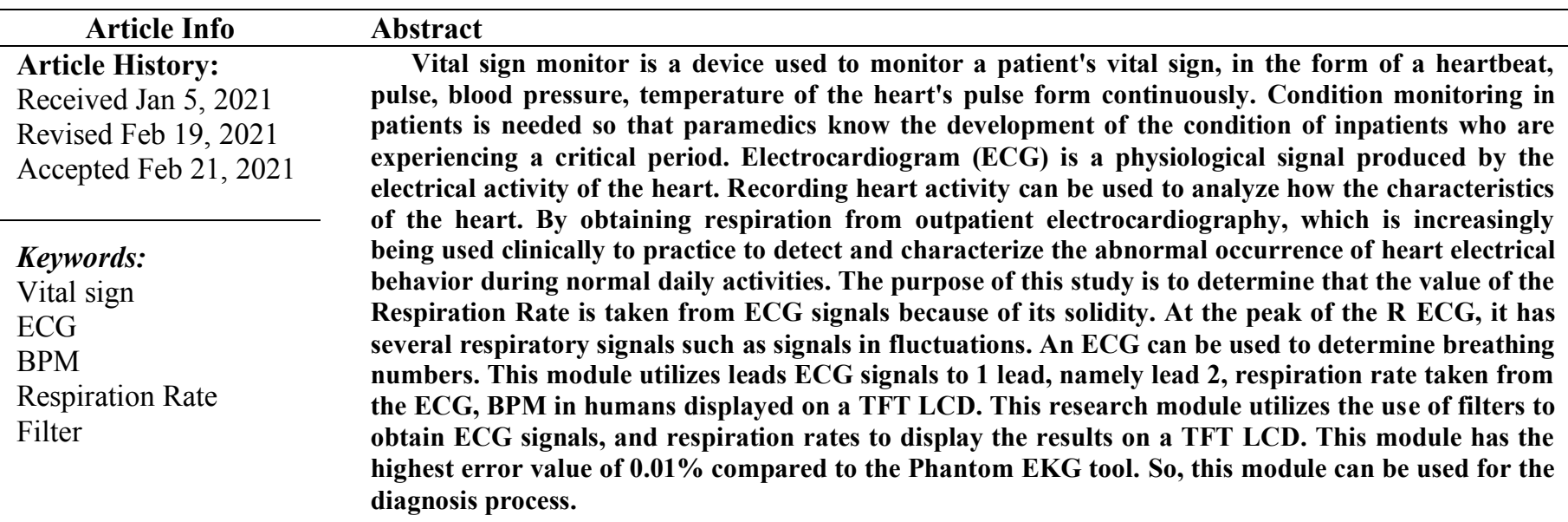

\section{Corresponding Author:}

andjar.pudji@gmail.com

Department of Medical Electronics Engineering

Technology, Poltekkes Kemenkes Surabaya
This work is an open access article and licensed under a Creative Commons Attribution-ShareAlike 4.0 International License (CC BY-SA 4.0).

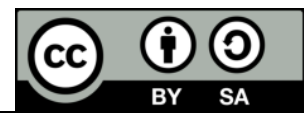

\section{INTRODUCTION}

An electrocardiogram (ECG) signal is an electrical signal produced by the electrical activity of the heart. Abnormalities of a person's heart function can be seen from this ECG signal recording. A cardiologist evaluates ECG signal records from waveforms, duration, signal orientation and signal rhythm. The heart is one of the most important organs in the human body that plays a role in the circulatory system which functions to pump blood to the lungs and to all parts of the body and is located in the chest cavity between the two lungs[1][2]. ECG and respiration modules are 2 systems that can be recorded through lead II through the chest cavity[3].

ECG signals that have been described can be taken from a person's heart rate so that it can be used as one of the parameters to diagnose a heart disease with a beat unit (BPM).[4] Human heart rate values can be obtained with different values, for a normal heart rate a person is in the range of 60 to 100 beats per minute, but this can change with age and sex, and from that heart rate it can be concluded that when the heartbeat less than $60 \mathrm{bpm}$ is called Bradycardia whereas when a heart rate of $100 \mathrm{bpm}$ is called Tachycardia[5][6].

Breathing is the event of breathing air from outside which contains oxygen $(\mathrm{O} 2)$ into and exhales air that contains carbon dioxide (CO2) as a residue from oxidation to the outside of the body. In taking a breath into the body and exhaling into the air is done by two ways of breathing, namely chest breathing and abdominal breathing[7][8]. Respiration is an important physiological parameter that helps provide information about a patient's health status[9][10] A respiration rate is a tool used to calculate the respiratory rate within 1 minute, this measurement can be used to diagnose an illness[11][12] ( Bestari, 2016).

Research The emergence of the breathing cycle in heart rate signals (respiratory sinus arrhythmia) is not new and many techniques have been developed to obtain respiration rates[13][14]. By obtaining respiration from outpatient 
electrocardiography, which is increasingly being used clinically to practice to detect and characterize the abnormal events of the heart's electrical behavior during ordinary daily activities. At peak R ECG has several respiratory signals such as signals in fluctuations. An ECG can be used to determine breathing numbers. When the ECG signal is good, the accuracy of the respiratory rate is as high as 90\%.[15]. Previously, the same tool was made by Raden Duta Ikrar and Farah Diska in 2016 for monitoring heart rate, respiration rate equipped with temperature sensor [16][17]. Furthermore, the devices have developed by Ghofar Nur Eka Susilo in 2017 also proposed patient monitor with ECG and temperature parameters. Moreover, this devices was developed again by M. Alfani burhanuddin in 2019 [18][19]. Based on the results of the identification of chronological problems above and pay attention to the results of the evaluation through analysis on the previous tool, the authors want to design a patient monitor device (ECG signal tapping on 1 lead that is lead 2, respiration rate taken from ECG, Bpm, Temperature, and SPO2) on human being displayed on a TFT LCD.

This article consists of 5 parts. Part II contains the Material and Method of tool design, Part III contains the results obtained in the form of a series of drawings, a list of programs and the display of envelope signals on Android, Part IV contains a discussion of the results of this study, Part V contains the conclusions obtained. Materials and methods

\section{A. Experimental Setup}

This study uses phantom ECG with the brand fluke as a comparison and subjects with the age of 21 years. The patient is in a relaxed or sleepy / non-movement condition

\section{B. Materials and Device}

The tapping series consists of a series of Instrumentation, amplifiers, HPF filters $-20 \mathrm{~dB}$ with a cut off of $0.031 \mathrm{~Hz}$ and LPF $-120 \mathrm{~dB}$ with a cut off of $0.4 \mathrm{~Hz}$. Using a 12 -volt battery and a Charger module board, Stepdown 9V and 5V 1A. Use IC TL 074 to process ECG signals. Experiment

In this research, the writer can ensure that respiration rate can be taken through ECG by using 1 lead, 2 leads

\section{The Diagram Block}

Electrodes that have been installed will detect the heart's electrical signals. Because the heart's electrical signal is very small, in the order of a millivolt, it is amplified by a series of instrumentation amplifiers so that the output is volt-order. The output signal from the amplifier instrument is filtered to remove the noise signal and the interference will then be converted into digital data by the ADC from Arduino. Furthermore, the data is processed by the Arduino program and then displayed on the monitor in graphical form, the Bpm Value, and the LCD TFT display is also available to display the values of all parameters.

Electrodes that have been attached to the chest will detect pulmonary electrical signals. Because the pulmonary signal is smaller than the electrical signal of the heart, in the order of a millivolt, it is amplified by a series of instrumentation amplifiers so that the output is volts. The output signal from the amplifier instrument is filtered to remove the noise signal and the interference will then be converted into digital data by the ADC from Arduino. Furthermore, the data is processed by the Arduino program and then displayed on a monitor in graphical form and on the device also available LCD TFT to display the values of all parameters (fig 1).

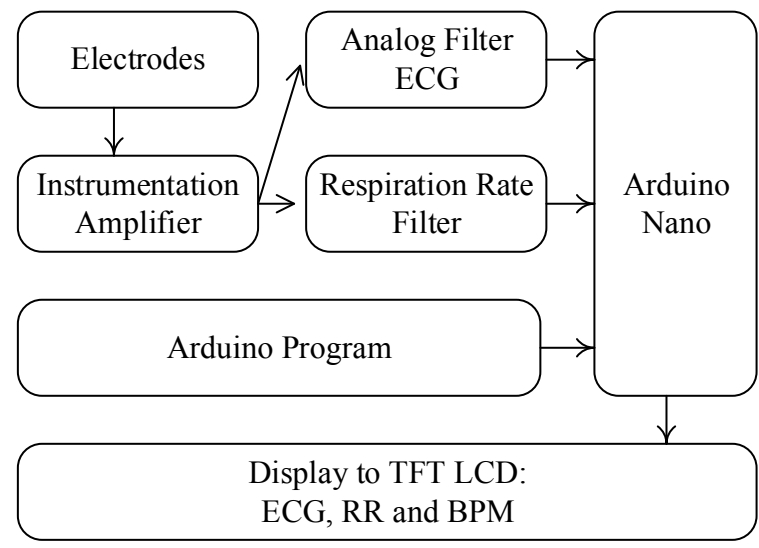

Fig 1 Electric Wheelchair Blok Diagram

D. The Flowchart

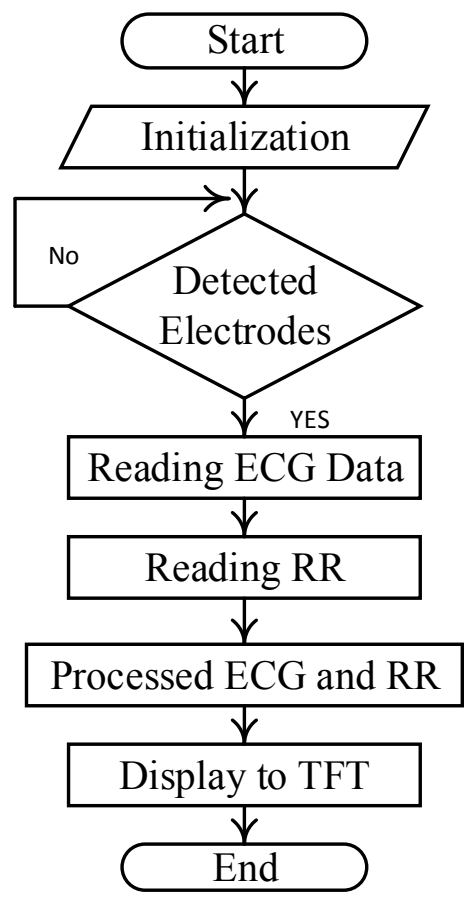

Fig 2 Flowchart of ECG and RR

When the instrument is turned on the electrode will detect the electrical signal of the patient's heart, then the detected signal 
will be processed by the ADC microcontroller then ECG signal, the Respiration Rate signal and the Bpm Value will be displayed on the TFT LCD (fig.2).

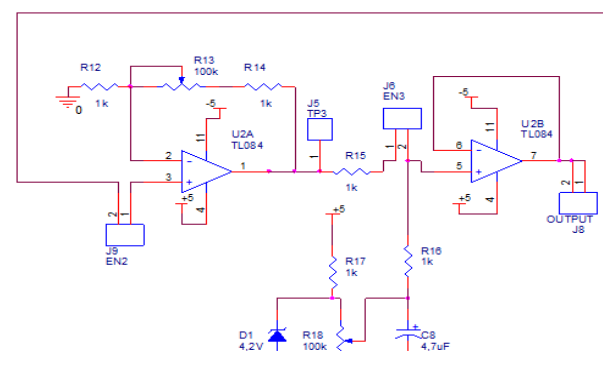

Fig. 3 HPF and Non-Inverting Circuits

HPF is a type of filter that passes high frequencies, but reduces the frequency amplitude which is lower than the cut off frequency. The simplest HPF consists of a capacitor connected in parallel with a resistor. Op-Amp Non-Inverting amplifier is a series of Op-Amp that works as a voltage amplifier at a positive input voltage $(\mathrm{V}+)$. In this circuit the amplification results in the op-amp's output voltage will be in phase $(0)$ of the input voltage or in other words if the input voltage is a positive voltage then the output will be a positive voltage as well, and likewise the negative input voltage. (fig 3 )

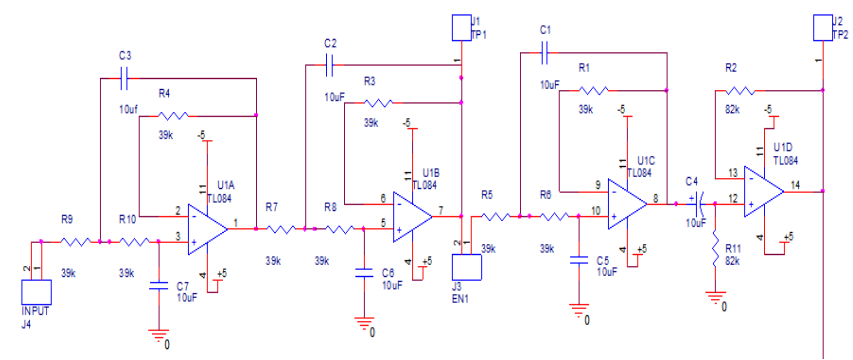

Fig. 4 Low Pass Filter Circuit

Low Pass Filter (LPF) is a filter that only passes signals with frequencies lower than the cut off frequency $(\mathrm{Fc})$ and will weaken the signal with a frequency higher than the cut off frequency $(\mathrm{Fc})$. In an ideal LPF filter signal with a frequency above the cut off frequency $(\mathrm{Fc})$ will not be missed at all (output voltage $=0$ Volts) (fig.4)

\section{RESULTS}

\section{A. Results of Lead Circuit design}

In (Fig. 5), the researcher measures the heart rate (BPM) of the phantom ECG and the respiration rate (RR) value of the randomly chosen respondent and the results are compared with the standard.
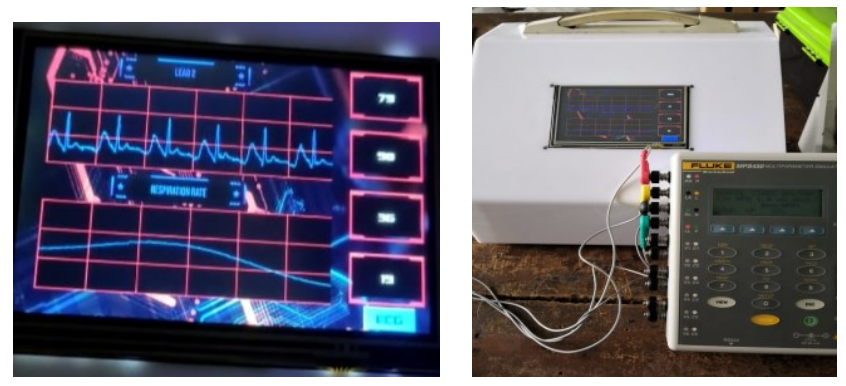

Fig.5 Results of responden and phantom

\section{B. Listing program for ECG and RR Initialization}

The above program is used to enter variable initialization to give commands.

\author{
Listing program 1. Initialization \\ int lead2 = A1; \\ int inputPin $=\mathrm{A} 3$; \\ Value2 $=\operatorname{map}(\operatorname{analogRead}($ lead2 $), 0,1024,0,128)$; \\ Value $4=\operatorname{map}($ resp $, 0,1024,0,150)$;
}

\section{Listing program for BPM}

The above program explains that the output EKG leads are connected A1 to do BPM value processing using autoreference, where there is a use of hold which states the recalculation when it meets the requirements specified above.

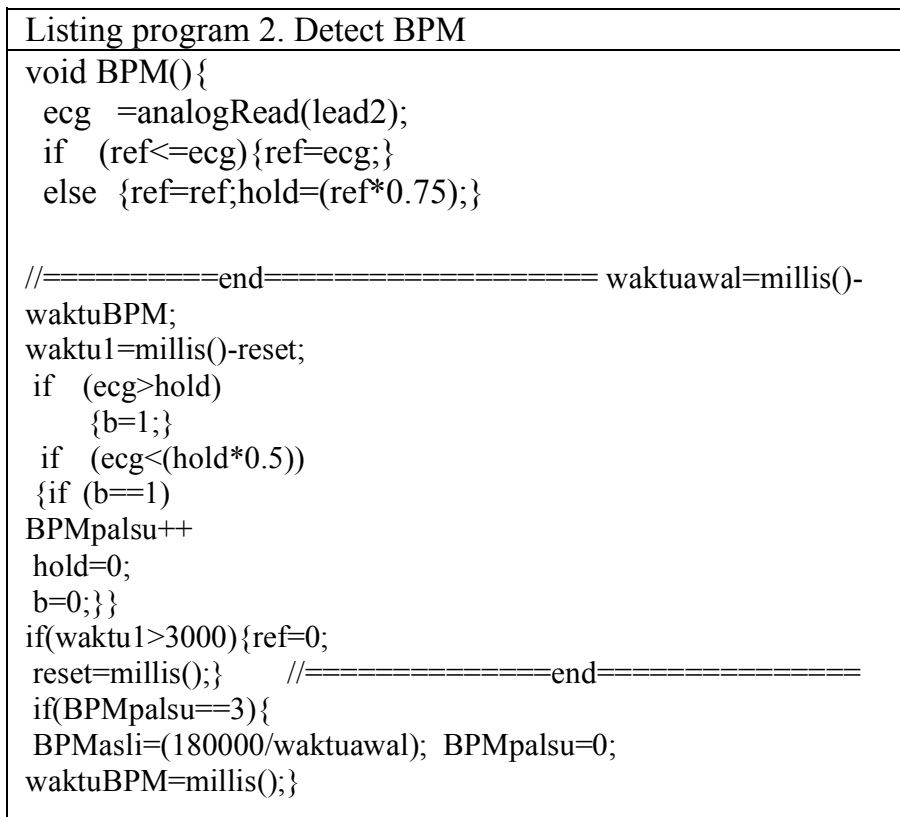

\section{Accredited by Ministry of Research and Technology /National Research and Innovation Agency Decree No: 200/M/KPT/2020




\section{Listing program for respiration rate}

The above program explains that the output of connected A3 ECG leads is carried out to treat respiration values using autoreference, where there is a use of hold which states the recalculation when it meets the requirements set out above.

\begin{tabular}{|l}
\hline Listing program 3. Detect RR \\
void RR() \{ \\
total = total - readings[readIndex]; readings[readIndex] = \\
analogRead(inputPin); total = total + readings[readIndex]; \\
readIndex $=$ readIndex $+1 ;$ \\
if (readIndex $>=$ numReadings) \\
readIndex $=0 ;\}$ \\
resp $=$ total / numReadings; \\
if (refrr $<=$ resp) $\{$ refrr $=$ resp; \\
else $\{$ refrr $=$ refrr;holdrr $=($ refrr* 0.8$) ;\}$ \\
$/ /==========================$ end $=========$
\end{tabular}

$/ /$ deteksi(); //======== pembacaan ketika ada

nafas $=======$

waktu=millis()-waktureset;

if (resp>holdrr) \{

beat $=1 ;\}$ if $($ resp $<($ holdrr*0.95) $)\{$

if $($ beat $==1)\{$

nafasmanual++;

holdrr $=0$;

\section{E. Listing program for shipping to TFT}

The above program is a program sending several parameters to the TFT LCD. The program must be connected to the frame that was created in Nextion Editor by using the default RX TX communication from arduino mega2560. The author intentionally equates the delay (mailing list) between sending parameters both BPM and respiration rate to the TFT LCD.

\section{Listing program 3 . Send data to TFT}

if(millis()-Report>waktukirim) \{

Serial.print("n0.val=");

Serial.print(nafasmenit);

Serial.write(0xff);

Serial.write(0xff);

Serial.write(0xff);

\section{F. BPM measurement results from Phantom}

TABLE I. BPM MEASUREMENT RESULT FOR RESPONDEN

\begin{tabular}{ccccccccccc}
\hline & \multicolumn{3}{c}{ Reading on Devices (BPM) } & \multicolumn{5}{c}{ Reading on Calibrator (BPM) } \\
\cline { 2 - 10 } & 30 & 60 & 120 & 180 & 240 & 30 & 60 & 120 & 180 & 240 \\
\hline 1 & 30 & 60 & 120 & 180 & 240 & 30 & 60 & 120 & 179 & 240 \\
\hline 2 & 30 & 60 & 120 & 180 & 240 & 30 & 60 & 120 & 181 & 240 \\
\hline 3 & 30 & 60 & 120 & 181 & 240 & 30 & 60 & 120 & 180 & 240 \\
\hline 4 & 30 & 60 & 120 & 180 & 240 & 30 & 60 & 120 & 180 & 240 \\
\hline 5 & 30 & 60 & 120 & 180 & 240 & 30 & 60 & 120 & 180 & 240 \\
\hline mean & 30 & 60 & 120 & 180.2 & 240 & 30 & 60 & 120 & 180 & 240 \\
\hline
\end{tabular}

Based on the measurement results in table I, ECG reader results are obtained with some standard values obtained from the ECG phantom. On the results of testing the tool using a calibrator / phantom ECG with a sensitivity of $1 \mathrm{mV}$ in table I obtained an error value of

TABLE II. THE RESULTS OF THE MEASUREMENT ERROR VALUE OF BPM FROM PHANTOM

\begin{tabular}{cccccc}
\hline \multirow{2}{*}{ No } & \multicolumn{6}{c}{ ERROR } \\
\cline { 2 - 6 } & 30 & 60 & 120 & 180 & 240 \\
\hline 1 & 0 & 0 & 0 & 0.006 & 0 \\
\hline 2 & 0 & 0 & 0 & -0.01 & 0 \\
\hline 3 & 0 & 0 & 0 & 0.006 & 0 \\
\hline 4 & 0 & 0 & 0 & 0 & 0 \\
\hline 5 & 0 & 0 & 0 & 0 & 0 \\
\hline
\end{tabular}

TABLE III.

RESPIRATION RATE MEASUREMENT

\begin{tabular}{cccc}
\hline No. & Gender $(\mathrm{M} / \mathrm{F})$ & Ages (years) & Value \\
\hline 1 & $\mathrm{M}$ & 20 & 19 \\
\hline 2 & $\mathrm{M}$ & 19 & 40 \\
\hline
\end{tabular}

Based on the measurement results in Table III, the reading of the module with multiple nails has an error value of 40 in patient no. 2 because the results of the counter system are not yet perfect, the refinement of the counters requires additional circuits, but is not carried out due to time and condition constraints.

\section{DISCUSSION}

In this study, the authors took data from a phantom ECG device and patients aged 21 years. where in the $1 \mathrm{mv}$ sensitivity setting with BPM 30, 60, 80, 120, 180 and 240. Based on the data displayed on the graph and the value shows

\section{Accredited by Ministry of Research and Technology /National Research and Innovation Agency Decree No: 200/M/KPT/2020


that each ECG can be taken Rr using 1 lead value that is lead 2 . When compared with research conducted by [17][14][16] this research can be used by people with tetraplegia and have used wireless systems. The weakness of the designed system is that the electrode settings in the patient must be in the right position and need to re-calculate the filter to get a better Respiration rate measurement.

\section{CONCLUSION}

The purpose of this study was to design a vital sign monitor for patients in the ED. This study found what is meant by many references that can be used to compare ECG signals RR signals and BPM values of patients. In summary, this study uses upper and lower thresholds to detect patient signals. when the patient signal matches the threshold, it sends a value and will continue to send the value until the patient signal is less than the lower limit or the sensor has been pulled. In the future the authors hope to develop a reference approval system that the Respiration rate can be taken through the ECG

\section{REFERENCES}

[1] A. Rizal and V. Suryani, "Pengenalan Signal EKG Menggunakan Dekomposisi Paket Wavelet dan K-Means Clustering," Proceeding Semin. Nas. Apl. Teknol. Inofrmasi 2008(SNATI 2008), vol. 2008, no. Snati, pp. 5-8, 2008.

[2] F. Tancini et al., "1,1-Dicyano-4-[4-(diethylamino)phenyl]buta-1,3dienes: Structure-property relationships," European J. Org. Chem., no. 14, pp. 2756-2765, 2012.

[3] "MAKALAH PASIEN MONITOR PERALATAN DIAGNOSTIC DASAR Aulad Satria Gibratar BINA BANGSA SEMARANG," 2014.

[4] R. M. Lang et al., "Recommendations for cardiac chamber quantification by echocardiography in adults: An update from the American Society of Echocardiography and the European Association of Cardiovascular Imaging," J. Am. Soc. Echocardiogr., vol. 28, no. 1, p. 1-39.e14, 2015.

[5] H. AL-Ziarjawey, "Heart Rate Monitoring and PQRST Detection Based on Graphical User Interface with Matlab," Int. J. Inf. Electron. Eng., vol. 5, no. 4, pp. 311-316, 2015.

[6] V. Khambhati, "A Review on Respiration Rate Estimation from ECG Signal,” no. February, pp. 2-5, 2017.

[7] B. Pambianco, A. Sbrollini, I. Marcantoni, M. Morettini, S. Fioretti, and L. Burattini, "Electrocardiogram Derived Respiratory Signal through the Segmented-Beat Modulation Method," Proc. Annu. Int. Conf. IEEE Eng. Med. Biol. Soc. EMBS, vol. 2018-July, pp. 5681-5684, 2018.

[8] D. Caggiano and S. Reisman, "Respiration derived from the electrocardiogram: a quantitative comparison of three different methods," Bioeng. Proc. Northeast Conf., pp. 103-104, 1996.

[9] A. S. Ecg, J. Boyle, N. Bidargaddi, and A. Sarela, "Automatic Detection of Respiration Rate From,” vol. 13, no. 6, pp. 890-896, 2009.

[10] P. De Chazal and N. Sadr, "Sleep apnoea classification using heart rate variability, ECG derived respiration and cardiopulmonary coupling parameters," Proc. Annu. Int. Conf. IEEE Eng. Med. Biol. Soc. EMBS, vol. 2016-Octob, pp. 3203-3206, 2016.

[11] R. Dqg et al., “6FKRRO RI , QIRUPDWLRQ ( QJLQHHULQJ / RQJ DQ 8QLYHUVLW $\backslash$ ) XMLDQ \& KLQD,” vol. 1, pp. 408-412, 2017.

[12] B. Mazzanti, C. Lamberti, and J. De Bie, "Validation of an ECG-derived respiration monitoring method," Comput. Cardiol., vol. 30, pp. 613-616, 2003.

[13] L. Zhao, S. Reisman, and T. Findley, "Derivation of respiration from electrocardiogram during heart rate variability studies,” pp. 53-56, 2002.

[14] M. H. Imam, C. K. Karmakar, A. H. Khandoker, and M. Palaniswami, "Effect of using ECG derived respiration (EDR) signal in linear parametric QT-RR modeling," Proc. Annu. Int. Conf. IEEE Eng. Med. Biol. Soc. EMBS, pp. 1968-1971, 2013.

[15] H. Kuo, C. Y. Christian, and C. Y. Christian, "Using ECG Surface Electrodes in Measurement of Respiration Rate for Preterm Infants," pp. 12-15, 2014.

[16] G. Lenis, F. Conz, and O. Dössel, "Combining different ECG derived respiration tracking methods to create an optimal reconstruction of the breathing pattern," Curr. Dir. Biomed. Eng., vol. 1, no. 1, pp. 54-57, 2015.

[17] K. Rajkumar and K. Ramya, "Respiration rate diagnosis using single lead ECG in real time," Glob. J. Med. Res., vol. 13, no. 1, pp. 7-11, 2013.

[18] V. Khambhati and M. B. Patel, "Extraction of a respiration rate from ECG signal using discrete wavelet transform during exercise," Imp. J. Interdiscip. Res., vol. 3, no. 2, pp. 1238-41, 2017.

[19] D. Widjaja, C. Varon, A. Dorado, J. A. K. Suykens, and S. Van Huffel, "Application of kernel principal component analysis for single-leadECG- derived respiration,” IEEE Trans. Biomed. Eng., vol. 59, no. 4, pp. 1169-1176, 2012. 